\title{
In vitro and in vivo cytotoxicity of troglitazone in pancreatic cancer
}

\author{
Megumi Fujita, Ai Hasegawa, Motohiro Yamamori and Noboru Okamura*
}

\begin{abstract}
Background: Troglitazone (TGZ) is a peroxisome proliferator-activated receptor gamma (PPARY) agonist that has been investigated as a potential chemopreventive and chemotherapeutic agent. However, the antitumor efficacy and mechanisms of TGZ in pancreatic cancer have not been extensively investigated. This study was performed to investigate the in vitro and in vivo effects of TGZ against pancreatic cancer cell lines, as well as its action mechanisms in terms of PPARy dependency and the Akt and mitogen-activated protein kinase (MAPK) pathways. We also evaluated the effects of TGZ on cell invasion and migration.

Methods: MIA Paca2 and PANC-1 human pancreatic cancer cell lines were used. Cell viability and caspase-3 activity were detected using fluorescent reagents, and chromatin condensation was observed after staining the cells with Hoechst 33342. Protein expression levels were detected by western blot analysis. Invasion and migration assays were performed using 24-well chambers. The in vivo antitumor effects of TGZ were investigated in nude mice inoculated with MIA Paca2 cells. Mice were orally administered TGZ (200 mg/kg) every day for 5 weeks, and tumor volumes were measured bi-dimensionally.

Results: TGZ showed dose-dependent cytotoxicity against both cell lines, which was not attenuated by a PPARY inhibitor. Further, TGZ induced chromatin condensation, elevated caspase-3 activity, and increased Bax/Bcl-2 relative expression in MIA Paca2 cells. TGZ also increased phosphorylation of Akt and MAPK (ERK/p38/JNK) in both cell lines, and a JNK inhibitor significantly increased the viability of MIA Paca2 cells. TGZ moderately inhibited cell migration. Tumor growth in the MIA Paca2 xenograft model was inhibited by TGZ administration, while mouse body weights in the treated group were not different from those of the vehicle administration group.

Conclusion: We demonstrated for the first time the in vivo antitumor effects of TGZ in pancreatic cancer without marked adverse effects. TGZ induced mitochondria-mediated apoptosis in MIA Paca2 cells, and its cytotoxic effects were PPARY-independent and occurred via the JNK pathway. Our results indicate that TGZ is a potential approach for the treatment of pancreatic cancer and warrants further studies regarding its detailed mechanisms and clinical efficacy.
\end{abstract}

Keywords: Troglitazone, PPARY, Pancreatic cancer, Apoptosis, JNK MAPK, In vivo

\section{Background}

Pancreatic cancer is the fourth leading cause of cancerrelated deaths in Japan [1]. Although pancreatectomy is the most effective treatment at early stages, advanced pancreatic cancer is relatively resistant to chemotherapy and radiotherapy, and is still associated with a poor prognosis with a five-year survival rate of $7 \%$ in Japan for all five disease stages [1]. Gemcitabine has been the

\footnotetext{
* Correspondence: nokamua@mukogawa-u.ac.jp

Department of Clinical Pharmacy, School of Pharmacy and Pharmaceutical

Sciences, Mukogawa Women's University, 11-68 Koshien-kyuban-cho,

Nishinomiya, Hyogo 663-8179, Japan
}

standard therapy for advanced pancreatic cancer for over a decade [2]. Recently, monotherapy with S-1, an oral 5fluorouracil prodrug (tegafur) combined with two modulators (5-chloro-2, 4-dihydroxypyridine and potassium oxonate), was reported to extend both overall and relapse-free survival compared to that reported with gemcitabine [3]. Furthermore, additional novel combination therapies have been developed, such as gemcitabine plus erlotinib; a combination of leucovorin, 5fluorouracil, irinotecan, and oxaliplatin (FOLFIRINOX); and gemcitabine plus nab-paclitaxel. Although overall 
survival has been significantly prolonged with these regimens, the effect remains insufficient, and it is therefore necessary to develop a novel effective strategy for pancreatic cancer treatment.

Peroxisome proliferator-activated receptor gamma (PPAR $\gamma$ ) belongs to the nuclear hormone receptor transcription factor superfamily, playing major roles in adipogenesis, glucose metabolism, and angiogenesis [4]. PPAR $\gamma$ is expressed in a variety of normal tissues and tumor sites [5-7], as well as in pancreatic cancer $[8,9]$. While the role of PPARY in tumor sites remains poorly defined, the thiazolidinedione family of PPARY agonists, such as troglitazone (TGZ), pioglitazone (PGZ) and rosiglitazone, have been shown to regulate growth and survival in a number of cancer cell lines [10], suggesting that TGZ may serve as an effective approach for the treatment of pancreatic cancer. TGZ has been reported to induce antitumor effects via multiple signaling mechanisms, but mainly in a PPAR $\gamma$-independent manner $[10,11]$. However, there have been few reports regarding the antitumor efficacy and mechanisms of TGZ in pancreatic cancer $[8,9]$. Moreover, there are no reports concerning PPARY dependency and in vivo antitumor efficacy of TGZ in pancreatic cancer cells, although PGZ was evaluated using an in vivo model [9].

In the present study, we investigated whether the PPARY agonist, TGZ, exhibited in vitro cytotoxicity against two human pancreatic cancer cell lines, and clarified its mechanisms in terms of PPARy dependency, apoptosis, and the mitogen-activated protein kinase (MAPK) pathway. Furthermore, we examined the effects of TGZ on cell invasion and cell migration, as well as in vivo antitumor effects.

\section{Methods}

\section{Chemicals}

TGZ and pioglitazone were purchased from LKT Laboratories (St. Paul, MN) and BioVision (Milpitas, CA), respectively, and were dissolved in dimethyl sulfoxide (DMSO, Nacalai Tesque, Kyoto, Japan) just before use. The final DMSO concentration in the media did not exceed 0.1\%. GW9662 (PPARY inhibitor), SP600125 (JNK inhibitor), and SB202190 (p38 inhibitor) were obtained from Merck Millipore (Billerica, MA).

\section{Cells and cell culture}

MIA Paca2 and PANC-1 cells were provided by the RIKEN BRC through the National Bio-Resource Project of the MEXT (Ibaraki, Japan), and were used as human pancreatic cancer cell models. They were cultured in DMEM (Wako Pure Chemical Industries, Osaka, Japan). Media were supplemented with $10 \%$ heat-inactivated fetal bovine serum (FBS; GIBCO', Thermo Fisher Scientific, Waltham, $\mathrm{MA}$ ) and $50 \mathrm{U} / \mathrm{mL}$ penicillin $-50 \mu \mathrm{g} / \mathrm{mL}$ streptomycin
(Nacalai Tesque). Cells were cultured in an atmosphere of $95 \%$ air and $5 \% \mathrm{CO}_{2}$ at $37{ }^{\circ} \mathrm{C}$ and were subcultured every 3 or 4 days.

\section{Cell viability}

Cell viability was measured with Cell Quanti-Blue ${ }^{\mathrm{m}}$ (BioAssay Systems, Hayward, CA). Briefly, cells were seeded into 96-well plates (Asahi Glass, Tokyo, Japan) at a density of $1 \times 10^{4}$ cells/well and incubated for $24 \mathrm{~h}$. The cells were treated with TGZ in the presence or absence of other chemicals for a further $24 \mathrm{~h}$ using FBSfree medium. The assay utilizes the conversion of alamar blue reagent to fluorescent resorufin by metabolically active cells. The resorufin signal was measured in a CytoFluor Series 4000 Fluorescence Multi-Well Plate Reader (PerSeptive Biosystems, Framingham, MA) at an excitation wavelength of $530 \mathrm{~nm}$ and an emission wavelength of $580 \mathrm{~nm}$. The $50 \%$ growth inhibitory concentrations $\left(\mathrm{IC}_{50}\right)$ were calculated according to the sigmoid inhibitory effect model $E=\mathrm{IC}_{50}^{\gamma} /\left(\mathrm{IC}_{50}^{\gamma}+\mathrm{C}^{\gamma}\right)$, where $E$ represents the surviving fraction (\% of control), $\mathrm{C}$ represents the drug concentration in the medium, and $\gamma$ represents the Hill coefficient. For co-exposure studies, the TGZ dosage was set to approximately the $\mathrm{IC}_{50}$ value for each cell line.

\section{Detection of chromatin condensation (fluorescence microscopy)}

For nuclei staining, cells were treated with TGZ for $24 \mathrm{~h}$ at the $\mathrm{IC}_{50}$ concentrations for each cell line. Immediately after treatment, the nuclear chromatin of trypsinized cells was stained with $80 \mu \mathrm{g} / \mathrm{mL}$ Hoechst 33342 (Nacalai Tesque) in the dark at $20^{\circ} \mathrm{C}$ for $15 \mathrm{~min}$. They were then observed with a brightfield fluorescence microscope (VANOX; Olympus, Tokyo, Japan) under UV excitation. Cells with condensed chromatin were photographed at 40-fold magnification. In addition, at 20-fold magnification, more than 100 cells with condensed chromatin were counted in each experiment, and their percentage of the population was calculated.

\section{Antibodies}

Rabbit monoclonal antibodies against PPAR (81B8), Bax, Bcl-2, phospho-Akt (Ser473; D9E), and Akt (C67E7), phospho-ERK (Thr202/Tyr204; D31.14.4E), ERK (137 F5), phospho-JNK (Thr183/Tyr185; 81E11), JNK (56G8), phospho-p38 (Thr180/Tyr182; D3F9), and p38 (D13E1) were purchased from Cell Signaling Technology (Danvers, MA). Mouse monoclonal antibody against $\beta$-actin (C4) was from Santa Cruz Biotechnology (Dallas, TX). Horseradish peroxidase-linked goat antirabbit IgG was obtained from Santa Cruz Biotechnology and sheep anti-mouse IgG was obtained from GE Healthcare (Buckinghamshire, UK). 


\section{Western blot analysis}

Cells $\left(1.75 \times 10^{6}\right)$ were plated in 100 -mm dishes $24 \mathrm{~h}$ before treatment and then treated with TGZ $(50 \mu \mathrm{M})$ for 1 , 4,8 , or $24 \mathrm{~h}$. Cells were washed with ice-cold phosphate-buffered saline (PBS), harvested by scraping, and centrifuged at $300 \times g$ and $4{ }^{\circ} \mathrm{C}$ for $5 \mathrm{~min}$. Lysis buffer $\left(20 \mathrm{mM}\right.$ Tris (pH 7.5), $150 \mathrm{mM} \mathrm{NaCl}, 1 \%$ Triton $^{\mathrm{Tm}} \mathrm{X}$ $100,0.5 \%$ sodium deoxycholate, $1 \mathrm{mM}$ EDTA, $0.1 \%$ SDS, $1 \mathrm{mM} \mathrm{NaF}, 1 \mathrm{mM} \mathrm{Na} \mathrm{VO}_{4}$, and $0.1 \%$ protease inhibitor cocktail (Merck Millipore)) was added to pellets, and then cells were sonicated briefly, followed by incubation on ice for $20 \mathrm{~min}$. Cell extracts were centrifuged at $16,000 \times g$ and $4{ }^{\circ} \mathrm{C}$ for $15 \mathrm{~min}$, and supernatants were transferred to new tubes. Protein concentrations were determined by BCA protein assays. The samples were mixed with the same volume of $2 \times$ SDS-PAGE sample buffer containing $\beta$-mercaptoethanol (Nacalai Tesque) followed by boiling for $5 \mathrm{~min}$, and proteins ( $15 \mu \mathrm{g} / \mathrm{lane}$ ) were loaded onto $10 \%$ SDS-polyacrylamide gels. After electrophoresis, the proteins were transferred to a polyvinylidene difluoride membrane (GE Healthcare) and blocked with Tris-buffered saline- $0.1 \%$ Tween 20 (TBS-T) containing 2\% ECL Advance ${ }^{\mathrm{Tx}}$ Blocking Agent (GE Healthcare) for $1 \mathrm{~h}$. Blocked membranes were reacted with primary antibodies (diluted 1:10,000) for $1 \mathrm{~h}$ at $20^{\circ} \mathrm{C}$ followed by five washes with TBS-T. After incubation with the secondary antibody (diluted 1:25,000) for $1 \mathrm{~h}$ at $20{ }^{\circ} \mathrm{C}$, membranes were washed five times. Signal was visualized using ECL Advance ${ }^{\mathrm{mi}}$ detection reagents (GE Healthcare). Expression levels were analyzed using Image J software.

\section{Fluorometric assay of caspase- 3 activity}

Caspase-3 activity was assessed using a Fluorometric Caspase 3 Assay Kit (Merck Millipore) according to the manufacturer's instructions. Briefly, cells were seeded in 24-well plates at a density of $6 \times 10^{4}$ cells/well followed by $24 \mathrm{~h}$ incubation. After exposure to TGZ for $8 \mathrm{~h}$, the cells were harvested with lysis buffer (50 mM HEPES, $\mathrm{pH}$ 7.4, $5 \mathrm{mM}$ CHAPS, and $5 \mathrm{mM}$ DTT). The reaction buffer, including $16.6 \mu \mathrm{M}$ Acetyl-Asp-Glu-Val-Asp-7amido-4-methylcoumarin (Ac-DEVD-AMC), a caspase3 -specific substrate, was added to the wells, and the production of AMC was sequentially detected in a CytoFluor Plate Reader at an excitation wavelength of $360 \mathrm{~nm}$ and an emission wavelength of $460 \mathrm{~nm}$. Enzyme activities were determined as initial velocities expressed as nmol AMC/ $\mathrm{min} / \mathrm{mL}$, which were then corrected using the protein concentration in each well as determined by the BCA protein assay (Thermo Fisher Scientific).

\section{Invasion and migration assay}

An invasion assay was performed using 24-well BD

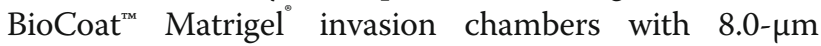

polycarbonate membrane filters (Corning; Corning, NY). Cells were seeded on membranes at a density of $2 \times 10^{5}$ cells/well with FBS-free medium; the membranes were placed into the lower chambers and 10\% FBS-containing medium was added. FBS was used as a chemoattractant. After being cultured with or without TGZ (maximum concentration without cytotoxicity: $10 \mu \mathrm{M}$ and $1 \mu \mathrm{M}$ in MIA Paca2 and PANC-1 cell lines, respectively) for $24 \mathrm{~h}$, cells on the upper surface of the membranes were removed using a cotton swab. Invasive cells that had penetrated through the membrane pores and migrated to the underside of the membranes were stained with Giemsa solution after fixation with $100 \%$ methanol. Cell numbers were quantified under a microscope, and the average cell number determined from quantification of four locations. The migration assay used the same protocol as the invasion assay except that non-coated chambers were used.

\section{Animal model}

Animal experiments were performed in accordance with the guidelines of the Institutional Animal Use Committee of Mukogawa Women's University, and the procedure was approved by the Committee. Balb/c male mice (4 weeks old) were purchased from Japan SLC (Shizuoka, Japan) and subcutaneously inoculated in the back with MIA Paca2 cells $\left(5 \times 10^{6}\right.$ cells $/ 100 \mu \mathrm{L}$ in PBS) 14 days prior to starting TGZ administration. Mice were then orally administered $200 \mathrm{mg} / \mathrm{kg}$ TGZ in $0.5 \%$ methylcellulose solution (Nacalai Tesque) or vehicle daily for 5 weeks. Tumor size was measured bidimensionally and the volume was calculated using the formula (length $\times$ width $\left.^{2}\right) \times 0.5$. Body weights of mice were also monitored throughout the experiment.

\section{Statistical analysis}

The data are expressed as the mean +/- the SD. Statistical significance was examined using Student's or Welch's $t$-test for comparing two groups. Nonrepeated one-way analysis of variance (ANOVA) followed by Dunnett's post-hoc test was used for multiple comparisons. $P<0.05$ was considered statistically significant.

\section{Results \\ Effect of TGZ and PGZ on cell viability}

Figure 1 shows the effects of TGZ and PGZ on the viability of the two pancreatic cancer cell lines. PGZ is another thiazolidinedione antidiabetic drug, and was used for comparison with TGZ. TGZ showed dosedependent cytotoxicity with $\mathrm{IC}_{50}$ values of $49.9 \pm 1.2$ and $51.3 \pm 5.3 \mu \mathrm{M}$ in MIA Paca2 and PANC-1 cells, respectively, whereas the $\mathrm{IC}_{50}$ values for $\mathrm{PGZ}$ were higher than $200 \mu \mathrm{M}$. 
MIA Paca2

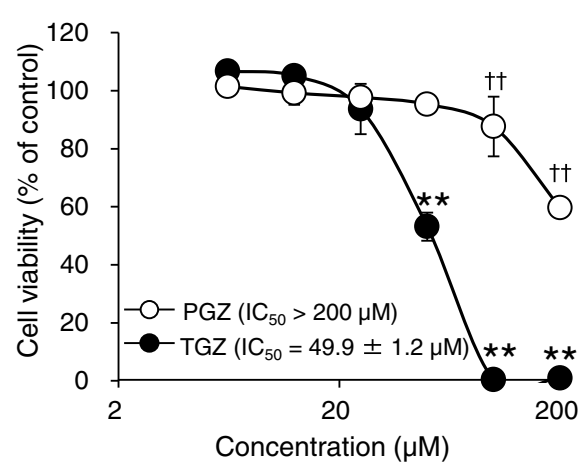

PANC-1

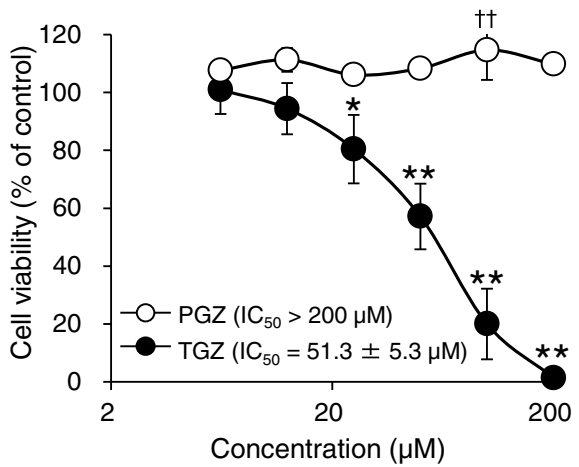

Fig. 1 Cytotoxic effects of troglitazone (TGZ) and pioglitazone (PGZ) in two pancreatic cancer cell lines. MIA Paca2 or PANC-1 cells were pre-cultured for $24 \mathrm{~h}$ at a density of $1 \times 10^{4}$ cells/well in 96-well plates and treated with TGZ or PGZ for $24 \mathrm{~h}$. Cell viability was assessed by fluorescence assay, and data represent the mean \pm SD from four independent preparations. Statistical significance was assessed by Dunnett's test (control vs. each concentration of TGZ). ${ }^{*} p<0.05$ and ${ }^{* *} p<0.01$ vs. control (for TGZ). $+p<0.05$ and $+\dagger p<0.01$ vs. control (for PGZ)

\section{Involvement of PPAR in effects of TGZ on cell viability}

To investigate the involvement of PPAR $\gamma$ in TGZmediated reduction of cell viability, we examined PPAR protein levels using western blotting and ascertained whether a PPAR $\gamma$ antagonist, GW9662, could recover cell viability. Although PPAR $\gamma$ was detected in both cell lines (Fig. 2a), $5 \mu \mathrm{M}$ of GW9662 did not increase the viability of TGZ-treated cells (Fig. 2b). We also conducted dose-response studies for GW9662 up to $20 \mu \mathrm{M}$, but cell viability was not rescued, and some cytotoxicity was observed when the cells were exposed to GW9662 at high concentrations (data not shown).
Effect of TGZ on nuclear morphology, caspase-3 activity, and $\mathrm{Bax} / \mathrm{Bcl}-2$ expression

Next, we conducted several experiments examining apoptosis. When cells were exposed to TGZ at $50 \mu \mathrm{M}$ for $24 \mathrm{~h}$, chromatin condensation, a typical morphological change characteristic of apoptosis, was observed after Hoechst 33342 staining. TGZ significantly increased the percentage of MIA Paca2 and PANC-1 cells showing chromatin condensation from 7 to $50 \%$ and from 2 to 24\%, respectively (Fig. 3a). TGZ also significantly increased the activity of caspase-3, a downstream component of the caspase cascade, by approximately 3.5-fold in MIA Paca2 cells, although no remarkable

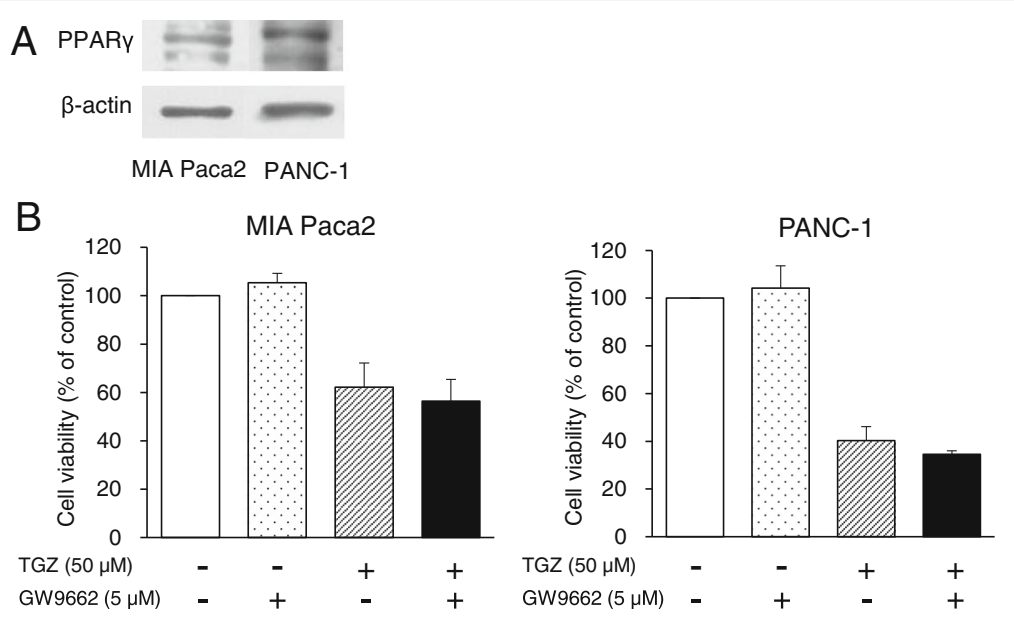

Fig. 2 PPARy protein expression and the effects of the PPARy inhibitor GW9662 on TGZ-induced cell death. a Cells $\left(1.75 \times 10^{6}\right)$ were incubated for $24 \mathrm{~h}$, and extracted protein $(15 \mu \mathrm{g})$ was analyzed by western blot for PPARY expression. $\mathbf{b}$ Cells were pre-cultured for $24 \mathrm{~h}$ at a density of $1 \times 10^{4}$ cells/well in 96-well plates and exposed to TGZ $(50 \mu \mathrm{M})$ with or without GW9662 $(5 \mu \mathrm{M})$ for $24 \mathrm{~h}$. Cell viability was assessed by fluorescence assay $(n=4-6)$. Statistical significance was assessed by $t$-test (TGZ vs. TGZ + GW9662, n.s., not significant). PPARy, peroxisome proliferator-activated receptor gamma; TGZ, troglitazone 

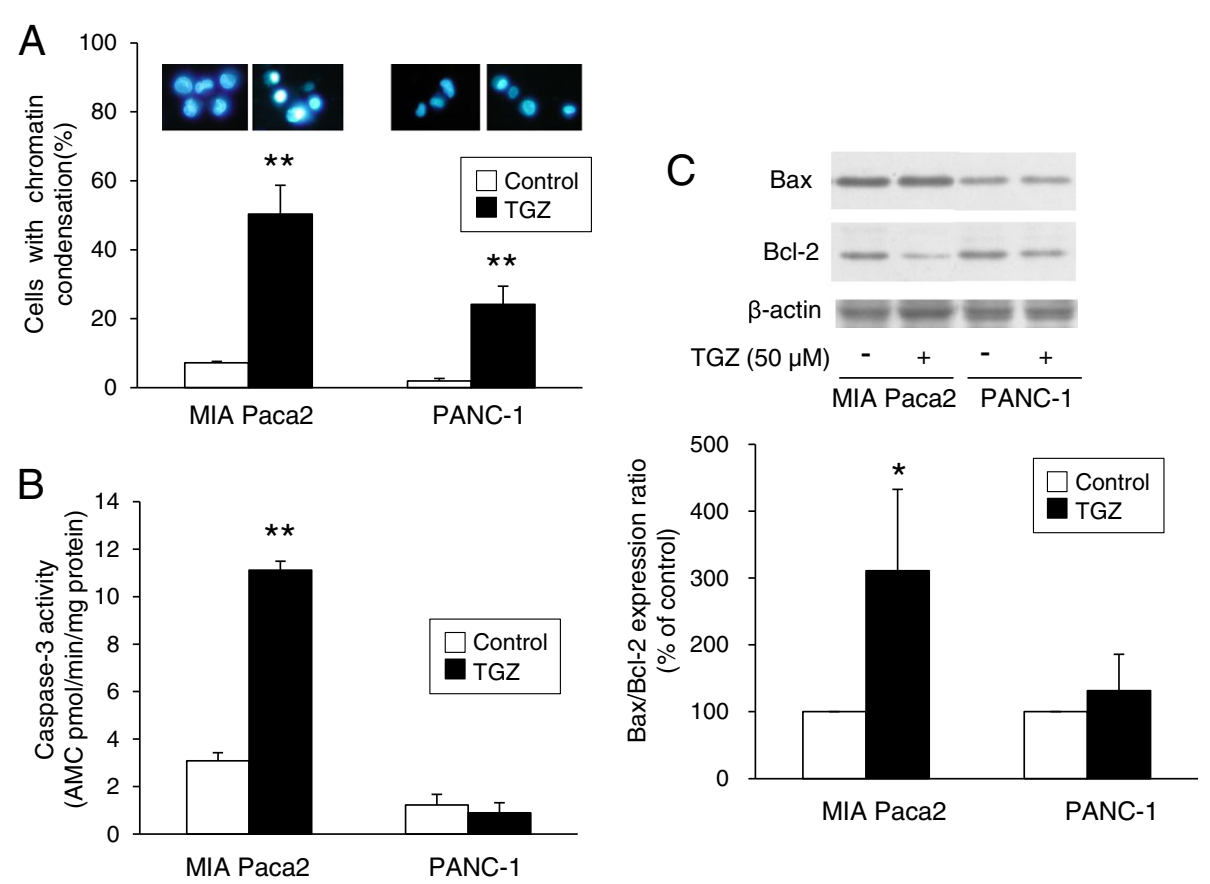

Fig. 3 Apoptosis assays for TGZ. a Representative fluorescence microscopy images of cells stained with Hoechst 33342 and the percentage of cells with chromatin condensation. Cells were treated with TGZ $(50 \mu \mathrm{M})$ for $24 \mathrm{~h}$ and stained with Hoechst 33342 for 15 min at $20{ }^{\circ} \mathrm{C}$. Cells were then observed using fluorescence microscopy under UV excitation, and the percentage of cells showing chromatin condensation was determined. Data represent the mean + SD from four independent preparations. b Effects of TGZ on caspase- 3 activity. Cells $\left(6 \times 10^{4}\right.$ cells/well) were seeded in 24-well plates followed by $24 \mathrm{~h}$ incubation. After exposure to TGZ $(50 \mu \mathrm{M})$ for $8 \mathrm{~h}$, caspase-3 activity was assessed using a fluorometric Caspase 3 Assay Kit. Enzyme activities were determined as initial velocities corrected by protein quantity $(n=4)$. c Bax and Bcl-2 protein expression. Cells $\left(1.75 \times 10^{6}\right)$ were incubated for $24 \mathrm{~h}$ and exposed to TGZ $(50 \mu \mathrm{M})$ for another $24 \mathrm{~h}$. Extracted protein $(15 \mu \mathrm{g})$ was analyzed by western blotting. Bcl-2 expression levels were corrected using $\beta$-actin and analyzed from three independent preparations. ${ }^{*} p<0.05$ and ${ }^{* *} p<0.01$ vs. control (t-test). TGZ, troglitazone

changes were observed in PANC-1 cells (Fig. 3b). Figure 3c shows the western blot analysis of the proapoptotic Bax protein and the anti-apoptotic Bcl-2 protein levels, which are involved in the mitochondrial apoptosis pathway. TGZ markedly decreased Bcl-2 expression by approximately $70 \%$ in MIA Paca2 cells and moderately decreased levels in PANC-1 cells. However, Bax expression was not significantly affected in both cell lines.

\section{Involvement of Akt and MAPK signaling in TGZ-induced cell death}

To examine the involvement of growth, survival, and death pathways, we examined the expression of the Akt and MAPK subfamily proteins: extracellular signalrelated kinase (ERK), c-Jun N-terminal kinase (JNK), and p38. TGZ increased the phosphorylation levels of all these proteins in both cell types, although the phosphop38 effect is not entirely clear with PANC-1 cells (Fig. 4a). As JNK and p38 are known to induce cell death, we also examined whether JNK and p38 inhibitors affected TGZ-induced cytotoxicity. We first confirmed that the phosphorylation of JNK was inhibited by SP600125 at $1 \mu \mathrm{M}$ (data not shown), and we had previously confirmed that $3 \mu \mathrm{M}$ of SB202190 completely blocked phosphorylation of p38 [12]. Co-exposure to $1 \mu \mathrm{M}$ SP600125 significantly elevated the viability of TGZ-treated MIA Paca2 cells, while no significant recovery was observed for PANC-1 cells (Fig. 4b). However, $3 \mu \mathrm{M}$ SB202190 did not attenuate TGZ cytotoxicity.

\section{Effects of TGZ on cell invasion and migration}

TGZ significantly reduced cell migration levels by approximately $20 \%$ compared to control migration values, whereas cell invasion levels were not affected (Fig. 5).

\section{In vivo antitumor effects of TGZ}

To clarify the effects of TGZ in controlling tumor growth in vivo, we administered TGZ to mice inoculated with MIA Paca2 cells. TGZ exhibited inhibitory effects on tumor growth in the MIA Paca2 xenograft model (Fig. 6a); however, the body weights of mice were not 

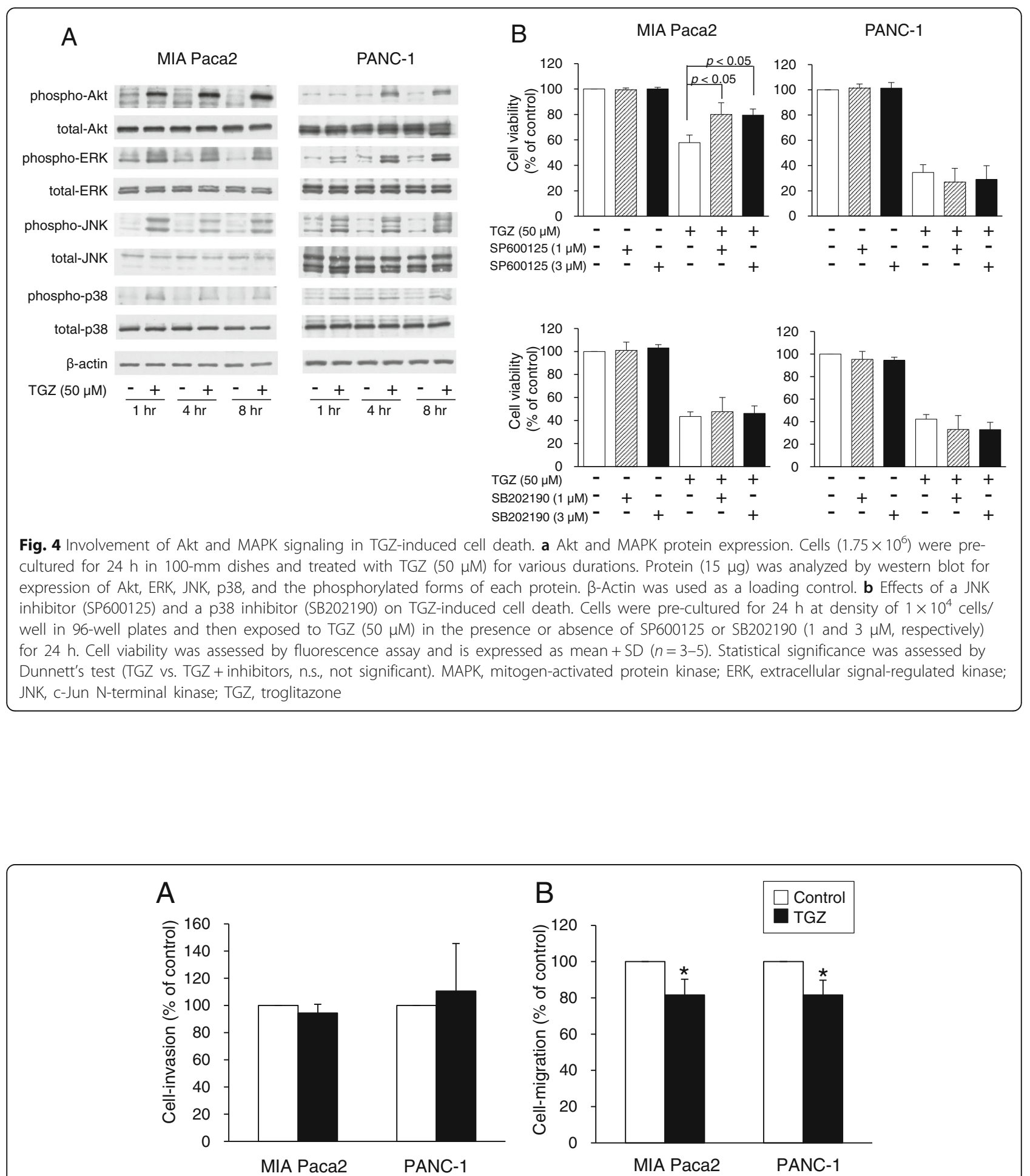

Fig. 5 Effects of TGZ on cell invasion and cell migration. a The cell invasion assay was performed using 24-well BD BioCoat ${ }^{\text {TM }}$ Matrige ${ }^{\circledR}$ invasion chambers with 8.0- $\mu \mathrm{m}$ polycarbonate membrane filters. Cells were seeded on membranes at $2 \times 10^{5}$ cells/well with FBS-free medium, after which the membranes were placed into the lower chamber and incubated with 10\% FBS-containing medium. After culture with or without TGZ (MIA Paca2: $10 \mu \mathrm{M}$, PANC-1: $1 \mu \mathrm{M}$ ) for $24 \mathrm{~h}$, cells on the upper surface of the membranes were removed using a cotton swab. Invasive cells that penetrated through the pores and migrated to the underside of the membrane were stained with Giemsa solution after fixation with $100 \%$ methanol. Cell number was quantified under microscopy. $\mathbf{b}$ The cell migration assay was conducted in the same manner as the cell invasion assay, except for the use of non-coated chambers. Data represent the mean + S.D. from three or four independent preparations. ${ }^{*} p<0.05$ vs. control (t-test). TGZ, troglitazone; FBS, fetal bovine serum 

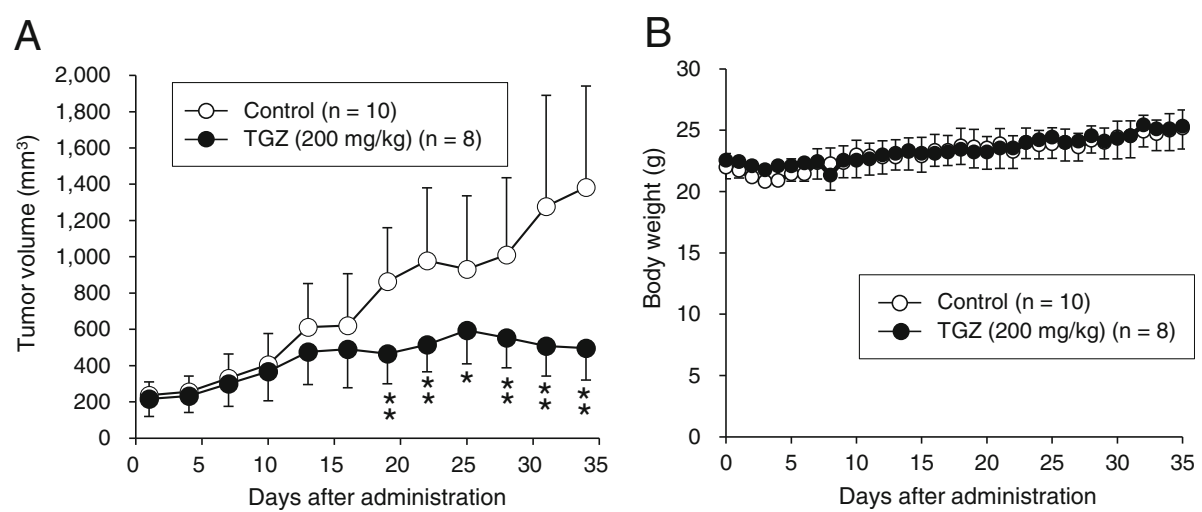

Fig. 6 In vivo antitumor effects of TGZ. a Tumor volume. Balb/c male mice were subcutaneously inoculated in the back with MIA Paca2 cells $\left(5 \times 10^{6}\right.$ cells) 14 days before the start of TGZ administration. Mice were then orally administered vehicle (control, $\left.n=10\right)$ or $200 \mathrm{mg} / \mathrm{kg}$ of TGZ $(n=8)$ daily for 5 weeks. Tumor volume was measured bi-dimensionally and volume was calculated by the formula (length $\times$ width $\left.{ }^{2}\right) \times 0.5$. b Mouse body weights were monitored throughout the experiment. Data are presented as mean \pm SD. ${ }^{*} p<0.05$ and ${ }^{* *} p<0.01$ vs. control on each individual day (t-test). TGZ, troglitazone

affected compared to those of the vehicle administration group (Fig. 6b).

\section{Discussion}

Pancreatic cancer has one of the poorest outcomes worldwide. While some effective chemotherapy measures have been reported recently, their efficacy unfortunately remains limited. As PPARY agonist thiazolidinediones have been shown to regulate growth and survival in a number of cancer cell lines [10], we designed this study to evaluate the antitumor effects of TGZ on pancreatic cancer cells in vitro and in vivo, and investigated its mechanism of cytotoxicity.

TGZ exhibited dose-dependent cytotoxicity with $\mathrm{IC}_{50}$ values of approximately $50 \mu \mathrm{M}$ and was more effective than PGZ was (Fig. 1). Similar to our results, previous reports have shown that TGZ showed higher efficacy than did the other thiazolidinediones [13-15], suggesting that TGZ could be a good antitumor candidate.

To investigate the association of PPAR $\gamma$ with TGZinduced cytotoxicity, we detected PPAR $\gamma$ protein levels and confirmed the effect of an irreversible PPAR $\gamma$ antagonist, GW9662, on TGZ-induced cell death. Although PPAR $\gamma$ was appreciably detected in both cell lines, GW9662 did not recover cell viability (Fig. 2), suggesting that the TGZ-mediated cytotoxic effect was PPAR $\gamma$ independent. The anticancer mechanisms of TGZ remain elusive, with the literature reporting both PPAR $\gamma$ dependent and independent cytotoxicity. For example, PPAR $\gamma$-dependent TGZ cytotoxicity was reported in lung cancer [16] and osteoblastic cells [17], while PPAR $\gamma$-independent cytotoxicity was observed in colon cancer [18], cervical cancer [15, 19], and prostate carcinoma [20]. Thus, the involvement of PPAR $\gamma$ in
TGZ-induced cytotoxicity seems to be cell typedependent. Itami et al. previously reported that TGZ enhanced the luciferase activity of the PPAR response element (PPRE) in pancreatic cancer cell lines [9], indicating that TGZ certainly activated PPAR $\gamma$ to bind PPRE in these cells. Conversely, TGZ exhibited higher cytotoxicity than PGZ did (Fig. 1), although the affinity of TGZ to PPARY is equal to that of PGZ [21]; this could be attributable to the differences in their chemical structure and partition coefficient, as well as their metabolism by the cells. Therefore, we concluded that the cytotoxic effect of TGZ in pancreatic cancer cells was independent of PPAR $\gamma$ activation.

To investigate the molecular mechanisms of TGZinduced cell death, we first examined the involvement of apoptosis. TGZ cytotoxicity was accompanied by chromatin condensation (Fig. 3a), caspase-3 activation (Fig. 3b), and an increased Bax/Bcl-2 ratio (Fig. 3c) in MIA Paca2 cells, suggesting that TGZ induced cell death through apoptosis via the mitochondrial pathway. In PANC-1 cells, TGZ induced chromatin condensation more modestly than in MIA Paca2 cells, but did not elevate caspase- 3 activity or increase the $\mathrm{Bax} / \mathrm{Bcl}-2$ ratio. Thus, other forms of death, such as caspase-independent apoptosis [14], autophagy, or necrosis, might participate to some extent in PANC-1 cells.

We next examined the involvement of cell growth, survival, and death signaling pathways. TGZ has been reported to regulate Akt and MAPK signaling $[12,17,22-26]$; therefore, we examined the phosphorylation of Akt and three classical MAPK proteins: ERK, JNK, and p38. Interestingly, Akt and ERK were activated by TGZ, although they are known to be involved in cell growth signaling (Fig. 4). Although Motomura et al. 
showed that TGZ reduced ERK signaling followed by inhibiting cell growth in pancreatic cancer cells [25], some groups reported opposite effects in other cancer cells, specifically that TGZ activated ERK and induced cell cycle arrest or cell death $[19,22,24,26]$. The reason for these inconsistent results is unclear. In addition, we examined the effects of an ERK inhibitor, U0126, and an Akt inhibitor on TGZ-induced cell death, and we did not observe recovery of cell viability (data not shown). This suggests that the activation of ERK and Akt may be caused by PPAR $\gamma$ activation by TGZ, but that their signaling is unrelated to TGZ cytotoxicity in MIA Paca2 and PANC-1 cells. We then examined the involvement of other MAPK signaling proteins, which are known to mediate cell death signaling. TGZ activated p38 signaling, but co-exposure to a p38 inhibitor, SB202190, showed no effect on cell viability, suggesting that $\mathrm{p} 38$ signaling also did not contribute to TGZ-induced cell death (Fig. 4). However, we confirmed that TGZ activated JNK signaling, and a JNK inhibitor, SP600125, significantly mitigated the cytotoxic effects of TGZ in MIA Paca-2 cells (Fig. 4). Previous reports showed that the activation of JNK signaling induced mitochondria-mediated apoptosis through regulation of the Bcl-2 family $[27,28]$. Taken together, the effects of TGZ in MIA Paca2 cells may very well occur through activation of JNK signaling and induction of apoptosis via reduction of Bcl-2 and activation of caspase- 3 . This is the first report to reveal the involvement of the JNK pathway in TGZ-mediated cytotoxicity in pancreatic cancer cell lines. However, the detailed mechanism in PANC-1 cells remains unclear. Several groups have revealed that TGZ caused $G_{1}$ phase arrest through the up-regulation of p21 and p27, and caused the activation of autophagy in pancreatic cancer $[9,29,30]$. Moreover, various pleiotropic mechanisms have been reported, such as the regulation of p53, GADD [22, 31], $\beta$-catenin [32], and $\mathrm{G}_{2} / \mathrm{M}$ arrest $[12,31]$, indicating that TGZ-mediated cytotoxicity in cancer cells may be attributable to "off-target" mechanisms [33]. Some of these mechanisms could be involved in PANC-1 cells. It also remains unclear why the mechanisms of action differed between the studied cell lines, and further studies are required.

As metastasis is one of the most common problems in pancreatic cancer, we next investigated the effects of TGZ on cell invasion and cell migration. While TGZ significantly inhibited cell migration, the overall magnitude of inhibition was slight (Fig. 5). Additionally, there was no effect on cell invasion, suggesting that TGZ had little effect on pancreatic cancer metastasis. In our experiments, we used lower concentrations of TGZ and observed no effect on cell viability. Motomura et al. [34] have shown that TGZ suppressed cell invasion or cell migration, but their experimental conditions were different in terms of TGZ concentration, type of chemoattractant used, and analysis undertaken. Based on our findings, we suggest that TGZ is not a good candidate for the suppression of pancreatic cancer metastasis. However, more confirmatory data are needed.

Since the in vivo effects of TGZ against pancreatic cancer have not been evaluated thus far, we administered TGZ to mice inoculated with MIA Paca2 cells. Tumor growth was significantly inhibited by TGZ administration, and the body weights of mice did not change (Fig. 6), suggesting the absence of marked adverse effects. TGZ was withdrawn from market as an antidiabetic drug because of severe liver toxicity [35]. On the other hand, existing non-oncological drugs could be useful for cancer therapy based on the notion of drugrepositioning [36]. Thus, TGZ could be an effective alternative for the treatment of pancreatic cancer. Moreover, combination therapy may be another useful strategy, as synergistic effects were reported with the combination of TGZ and chemotherapeutic agents [30, 37].

\section{Conclusions}

A PPAR $\gamma$ agonist, TGZ, showed cytotoxicity in two pancreatic cancer cell lines in a PPAR $\gamma$-independent manner. This study revealed that TGZ-mediated cytotoxicity occurred via the JNK pathway and mitochondria-mediated apoptosis, but our data also indicated the involvement of other types of cell death. In addition, we demonstrated, for the first time, the in vivo antitumor effects of TGZ in pancreatic cancer without marked adverse effects. Therefore, our study shows that TGZ administration might be a valuable approach for the treatment of pancreatic cancer, and TGZ warrants further investigation regarding its detailed mechanisms and clinical efficacy.

\section{Abbreviations}

ERK: Extracellular signal-regulated kinase; JNK: c-Jun N-terminal kinase; MAPK: Mitogen-activated protein kinase; PGZ: Pioglitazone; PPAR: Peroxisome proliferator-activated receptor; PPRE: PPAR response element; TGZ: Troglitazone

\section{Acknowledgements}

Not applicable.

\section{Funding}

This work was supported by a GRANT-in-Aid for Scientific Research (Grant Number JP15K08118) from the Ministry of Education, Culture Sports, Science, and Technology of Japan.

Availability of data and materials Not applicable.

\section{Authors' contributions}

Conception and design: MF, NO, Development of methodology: MF, NO, Acquisition of data: MF, Analysis and interpretation of data: MF, NO, Writing, review, and/or revision of manuscript: MF, NO, Administrative, technical, or material support: AH, MY, Study supervision: NO, All authors have read and approved the final manuscript.

Competing interests

The authors declare that they have no competing interests. 


\section{Consent for publication}

Not applicable.

\section{Ethics approval}

Animal care and experiments were performed in accordance with the guidelines of the Institutional Animal Use Committee of Mukogawa Women's University, and the procedure was approved by the Committee.

\section{Publisher's note}

Springer Nature remains neutral with regard to jurisdictional claims in published maps and institutional affiliations.

Received: 2 February 2017 Accepted: 18 June 2017 Published online: 03 July 2017

\section{References}

1. Cancer Registry and Statistics. Cancer Information Service. Japan: National Cancer Center; 2015. http://ganjoho.jp/reg_stat/statistics/dl/. Accessed 18 Jan 2017

2. Burris 3rd HA, Moore MJ, Andersen J, Green MR, Rothenberg ML, Modiano MR, et al. Improvements in survival and clinical benefit with gemcitabine as first-line therapy for patients with advanced pancreas cancer: a randomized trial. J Clin Oncol. 1997;15:2403-13.

3. Uesaka K, Boku N, Fukutomi A, Okamura Y, Konishi M, Matsumoto I, et al. Adjuvant chemotherapy of S-1 versus gemcitabine for resected pancreatic cancer: a phase 3, open-label, randomised, non-inferiority trial (JASPAC 01). Lancet. 2016;388:248-57.

4. Janani C, Ranjitha Kumari BD. PPAR gamma gene-a review. Diabetes Metab Syndr. 2015;9:46-50

5. Kubota T, Koshizuka K, Williamson EA, Asou H, Said JW, Holden S, et al. Ligand for peroxisome proliferator-activated receptor $\gamma$ (troglitazone) has potent antitumor effect against human prostate cancer both in vitro and in vivo. Cancer Res. 1998:58:3344-52.

6. Sarraf P, Mueller E, Jones D, King FJ, DeAngelo DJ, Partridge JB, et al. Differentiation and reversal of malignant changes in colon cancer through PPARY. Nat Med. 1998;4:1046-52.

7. Elstner E, Müller C, Koshizuka K, Williamson EA, Park D, Asou H, et al. Ligands for peroxisome proliferator-activated receptor $\gamma$ and retinoic acid receptor inhibit growth and induce apoptosis of human breast cancer cells in vitro and in BNX mice. Proc Natl Acad Sci U S A. 1998:95:8806-11.

8. Sasaki T, Fujimoto Y, Tsuchida A, Kawasaki Y, Kuwada Y, Chayama K. Activation of peroxisome proliferator-activated receptor gamma inhibits the growth of human pancreatic cancer. Pathobiology. 2001;69:258-65.

9. Itami A, Watanabe G, Shimada Y, Hashimoto Y, Kawamura J, Kato M et al. Ligands for peroxisome proliferator-activated receptor gamma inhibit growth of pancreatic cancers both in vitro and in vivo. Int J Cancer. 2001:94:370-6.

10. Fröhlich $\mathrm{E}$, Wahl R. Chemotherapy and chemoprevention by thiazolidinediones. Biomed Res Int. 2015;2015:845340.

11. Wei S, Yang J, Lee SL, Kulp SK, Chen CS. PPARgamma-independent antitumor effects of thiazolidinediones. Cancer Lett. 2009:276:119-24.

12. Fujita M, Yagami T, Fujio M, Tohji C, Takase $K$, Yamamoto $Y$, et al. Cytotoxicity of troglitazone through PPARy-independent pathway and p38 MAPK pathway in renal cell carcinoma. Cancer Lett. 2011;312:219-27.

13. Yamamoto $Y$, Nakajima M, Yamazaki H, Yokoi T. Cytotoxicity and apoptosis produced by troglitazone in human hepatoma cells. Life Sci. 2001;70:471-82.

14. Yoshizawa K, Cioca DP, Kawa S, Tanaka E, Kiyosawa K. Peroxisome proliferator-activated receptor gamma ligand troglitazone induces cell cycle arrest and apoptosis of hepatocellular carcinoma cell lines. Cancer. 2002;95:2243-51.

15. Al-Alem L, Southard RC, Kilgore MW, Curry TE. Specific thiazolidinediones inhibit ovarian cancer cell line proliferation and cause cell cycle arrest in a PPARY independent manner. PLOS One. 2011;6:e16179.

16. Kim HJ, Woo IS, Kang ES, Eun SY, Kim GH, Ham SA, et al. Phorbol ester potentiates the growth inhibitory effects of troglitazone via up-regulation of PPARgamma in A549 cells. Biochem Biophys Res Commun. 2006:349:660-7.

17. Jung JY, Yoo Cl, Kim HT, Kwon CH, Park JY, Kim YK. Role of mitogenactivated protein kinase (MAPK) in troglitazone-induced osteoblastic cell death. Toxicology. 2007;234:73-82.
18. Qiao L, Dai Y, Gu Q, Chan KW, Ma J, Lan HY, et al. Loss of XIAP sensitizes colon cancer cells to PPARgamma independent antitumor effects of troglitazone and 15-PGJ2. Cancer Lett. 2008;268:260-71.

19. Chang HK, Kim DS, Chae JJ, Kim M, Myong JP, Lee KH, et al. Inhibition of ERK activity enhances the cytotoxic effect of peroxisome proliferatoractivated receptor $\gamma$ (PPARY) agonists in HeLa cells. Biochem Biophys Res Commun. 2017:482:843-8.

20. Shiau CW, Yang CC, Kulp SK, Chen KF, Chen CS, Huang JW, et al. Thiazolidenediones mediate apoptosis in prostate cancer cells in part through inhibition of $\mathrm{BCl}-\mathrm{xL} / \mathrm{BCl}-2$ functions independently of PPARgamma. Cancer Res. 2005:65:1561-9.

21. Willson TM, Brown PJ, Sternbach DD, Henke BR. The PPARs: From orphan receptors to drug discovery. J Med Chem. 2000;43:527-50.

22. Yin F, Bruemmer D, Blaschke F, Hsueh WA, Law RE, Herle AJ. Signaling pathways involved in induction of GADD45 gene expression and apoptosis by troglitazone in human MCF-7 breast carcinoma cells. Oncogene. 2004;23:4614-23.

23. von Schwarzenberg K, Held SA, Schaub A, Brauer KM, Bringmann A, Brossart P. Proteasome inhibition overcomes the resistance of renal cell carcinoma cells against the PPARy ligand troglitazone. Cell Mol Life Sci. 2009:66:1295-308.

24. Cho DH, Choi YJ, Jo SA, Jo I. Nitric oxide production and regulation of endothelial nitric-oxide synthase phosphorylation by prolonged treatment with troglitazone: evidence for involvement of peroxisome proliferatoractivated receptor (PPAR) gamma-dependent and PPARgammaindependent signaling pathways. J Biol Chem. 2004;279:2499-506.

25. Motomura W, Tanno S, Takahashi N, Nagamine M, Fukuda M, Kohgo Y, et al. Involvement of MEK-ERK signaling pathway in the inhibition of cell growth by troglitazone in human pancreatic cancer cells. Biochem Biophys Res Commun. 2005;332:89-94.

26. Kim JA, Park KS, Kim HI, Oh SY, Ahn Y, Oh JW, et al. Troglitazone activates p21 Cip/NAF1 through the ERK pathway in HCT15 human colorectal cancer cells. Cancer Lett. 2002;179:185-95.

27. Park J, Kim I, Oh YJ, Lee K, Han PL, Choi EJ. Activation of c-Jun Nterminal kinase antagonizes an anti-apoptotic action of BCl-2. J Biol Chem. 1997;272:16725-8.

28. Dhanasekaran DN, Reddy EP. JNK signaling in apoptosis. Oncogene. 2008:27:6245-51.

29. Motomura W, Okumura T, Takahashi N, Obara T, Kohgo Y. Activation of peroxisome proliferator-activated receptor gamma by troglitazone inhibits cell growth through the increase of $\mathrm{p} 27^{\mathrm{KiP} 1}$ in human pancreatic carcinoma cells. Cancer Res. 2000;60:5558-64.

30. Vitale G, Zappavigna S, Marra M, Dicitore A, Meschini S, Condello M, et al. The PPAR- $\gamma$ agonist troglitazone antagonizes survival pathways induced by STAT-3 in recombinant interferon- $\beta$ treated pancreatic cancer cells. Biotechnol Adv. 2012;30:169-84.

31. Han C, Demetris AJ, Michalopoulos GK, Zhan Q, Shelhamer JH, Wu T. PPARgamma ligands inhibit cholangiocarcinoma cell growth through p53dependent GADD45 and p21 pathway. Hepatology. 2003;38:167-77.

32. Wei $S$, Lin LF, Yang CC, Wang YC, Chang GD, Chen $H$, et al. Thiazolidinediones modulate the expression of $\beta$-catenin and other cellcycle regulatory proteins by targeting the F-box proteins of Skp1-Cul1-Fbox protein E3 ubiquitin ligase independently of peroxisome proliferatoractivated receptor $\gamma$. Mol Pharmacol. 2007;72:725-33.

33. Weng JR, Chen CY, Pinzone JJ, Ringel MD, Chen CS. Beyond peroxisome proliferator-activated receptor $\gamma$ signaling: the multi-facets of the antitumor effect of thiazolidinediones. Endocr Relat Cancer. 2006;13:401-13.

34. Motomura W, Nagamine M, Tanno S, Sawamukai M, Takahashi N, Kohgo Y, et al. Inhibition of cell invasion and morphological change by troglitazone in human pancreatic cancer cells. J Gastroenterol. 2004:39:461-8.

35. Gale EA. Lessons from the glitazones: a story of drug development. Lancet. 2001:357:1870-5.

36. Würth R, Thellung S, Bajetto A, Mazzanti M, Florio T, Barbieri F. Drugrepositioning opportunities for cancer therapy: novel molecular targets for known compounds. Drug Discov Today. 2016:21:190-9.

37. Hamaguchi $N$, Hamada $H$, Miyoshi $S$, Irifune $K$, Ito R, Miyazaki $T$, et al. In vitro and in vivo therapeutic efficacy of the PPAR- $y$ agonist troglitazone in combination with cisplatin against malignant pleural mesothelioma cell growth. Cancer Sci. 2010;101:1955-64. 